\title{
ANÁLISE DOS GRANDES EPISÓDIOS DE INCÊNDIOS NO PARQUE NACIONAL DA CHAPADA DIAMANTINA: UMA ABORDAGEM POR SENSORIAMENTO REMOTO.
}

\author{
Cândida Caroline Souza de Santana Leite'; Ardemírio de Barros Silva²; Washington de \\ Jesus Sant'Anna da Franca Rocha ${ }^{3}$
}

\author{
1. Bolsista PIBIC/Fapesb, Graduanda em Geografia, Universidade Estadual de Feira de Santana, e-mail: \\ candidaleite.geo@gmail.com \\ 2. Orientador, Departamento de Exatas, Universidade Estadual de Feira de Santana, e-mail: abarros@uefs.br \\ 3. Co-orientador, Departamento de Exatas, Universidade Estadual de Feira de Santana, e-mail: wrocha@uefs.br
}

PALAVRAS-CHAVE: Unidade de conservação; índice de queimada; Incêndios florestais

\section{INTRODUÇÃO}

A ocorrência de incêndios na vegetação vem se tornando um problema recorrente, principalmente em biomas secos como caatinga e cerrado (drylands). Estudos como o de Hoffman (1999) apontam que a reprodução vegetal, assim como o tamanho e o crescimento dos organismos podem ser afetados diretamente pelas queimadas, que, sob esta perspectiva, constituem graves ameaças à biodiversidade dos ecossistemas.

O Parque Nacional da Chapada Diamantina (PNCD) criado em 1985 com o intuito de proteger amostras representativas da biodiversidade da Serra do Sincorá, destaca-se entre as Unidades de Conservação com maior ocorrência de focos de incêndios do Brasil (IBAMA, 2008).

Assim, a necessidade de estudar os incêndios ocorridos no Parque surge como forma de entender suas características e assim possibilitar ações preventivas mais eficientes.

A utilização do Sensoriamento Remoto para essa finalidade tem sido cada vez mais importante, visto que se trata de uma ferramenta muito útil no mapeamento de uso e cobertura da terra, e especificamente, para a detecção de cicatrizes de queimadas. A partir do Sensoriamento Remoto e suas técnicas, é possível obter informações sobre a localização e extensão das marcas de incêndios deixadas na vegetação, podendo inclusive monitorar a perda da biomassa decorrente deste processo.

Dentre as técnicas capazes de detectar áreas acometidas por incêndios na vegetação está a aplicação do índice espectral NBR (Normalized Burn Ratio), que consiste em uma razão normalizada entre bandas do infravermelho próximo e o infravermelho de ondas curtas para diferenciar o comportamento espectral da vegetação queimada e da vegetação sadia (ALLEN e SORBEL, 2008).

Sendo assim, a presente pesquisa objetiva identificar as áreas acometidas pelos incêndios de 2008 e 2015 no Parque Nacional da Chapada Diamantina- Bahia, a partir da utilização do índice espectral $N B R$.

\section{MATERIAIS E MÉTODOS}

- Caracterização da área de estudo

O Parque Nacional da Chapada Diamantina (figura 1) localiza-se no interior da ecorregião da Chapada Diamantina, na porção central do estado da Bahia, entre as coordenadas UTM 782073.567 - 8627087.939 / 727184.906 - 8539841.777, Zona 24 Sul, abrangendo 152 mil hectares desta área. 


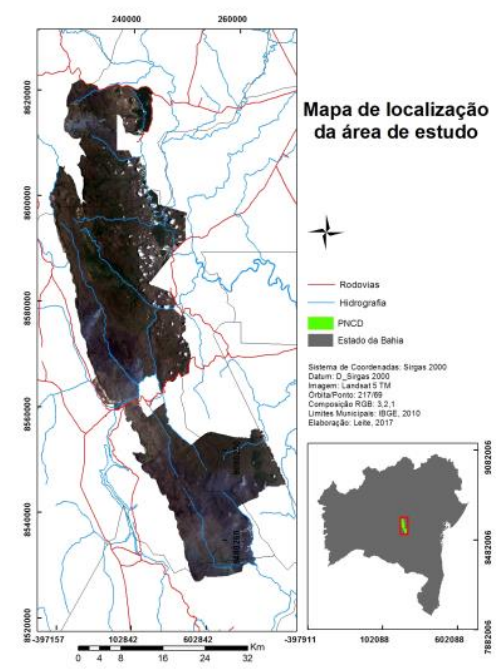

Figura 1: Mapa de localização da área de estudo

A área de estudo faz parte da porção norte da cadeia montanhosa da Serra do Espinhaço, com clima semi-árido em sua maior parte, com exceção de alguns enclaves de clima sub-úmido presente nas partes mais baixas dos numerosos vales ao longo do Parque. Além disso, a vegetação é composta por campos rupestres, vegetações de portes arbóreo até arbustivo (JUNCÁ, FUNCH E ROCHA, 2005).

- Aquisição e processamento de dados

Para este estudo foram utilizadas uma imagem do sensor TM (Thematic Mapper) a bordo do satélite LANDSAT 5 com data de passagem em 08 de novembro de 2008 e uma imagem do sensor OLI (Operation Land Imager) a bordo do satélite LANDSAT $8 \mathrm{com}$ data de passagem em 14 de novembro de 2015, ambas com órbita/ponto 217/69 e adquiridas através do banco de dados do Serviço Geológico do Estados Unidos (USGS- United States Geological Survey), pelo endereço eletrônico (http://earthexplorer.usgs.gov/).

A priori, a cena foi recortada a fim de delimitar a área de estudo, obtendo mais clareza e rapidez no processamento. Em seguida foi realizada a calibração radiométrica da imagem, a partir da função radiometric calibration, de modo a transformar os números digitais (ND) em valores de radiância.

A correção atmosférica das imagens foi efetuada com o módulo Quick Atmospheric Correction (QUAC), o qual, de acordo com ENVI (2017), aplica modelos empíricos, utilizando apenas as informações contidas na cena.

O índice espectral $N B R$ consiste em um método de identificação de parcelas de vegetação queimada, baseando-se na diferença normalizada entre o pico de reflectância no infravermelho próximo e do infravermelho de ondas curtas (ALLEN e SORBEL, 2008).

A equação 1, a seguir, define os termos da operação realizada:

$$
N B R=\frac{N I R-S W I R}{N I R+S W I R} \quad \text { Equação (1) }
$$

Sendo que, para o ano de 2008, (imagem Landsat 5) utilizou-se $N B R=\frac{R 4-R 7}{R 4+R 7}$ na qual, R4 equivale a reflectância da banda 4 da imagem Landsat 5 e R7 a reflectância da banda 7 da imagem Landsat 5 .

Quando utiliza-se imagem Landsat 8 aplica-se $N B R=\frac{R 5-R 7}{R 5+R 7}$ de modo que, R5 equivale a reflectância da banda 5 da imagem Landsat 8 e R7 a reflectância da banda 7 da imagem Landsat 8. 
As parcelas queimadas foram vetorizadas a partir das imagens índices fatiadas para determinado limiar. A quantificação da área queimada nas imagens índices foi realizada com o auxílio do software ArcGis 10.3. Todos os procedimentos de processamento digital de imagens foram baseados na metodologia utilizada por Leite et al. (2017).

Foi realizado um trabalho de campo no município de Lençóis a fím de validar os resultados de mapeamento de cicatrizes de incêndios para o ano de 2015. Na campanha de campo foram inspecionadas algumas das parcelas incendiadas em 2015, conforme o mapa de cicatrizes de incendios nesse ano, visando identificar vestígios, indícios ou marcas de ocorrências e vegetações queimadas.

\section{RESULTADOS E DISCUSSÃO}

A partir das imagens índices, resultantes do PDI com o $N B R$, foram elaborados os mapas de cicatrizes de incêndios dos anos estudados no PNCD (fig. 2 e 3 ).

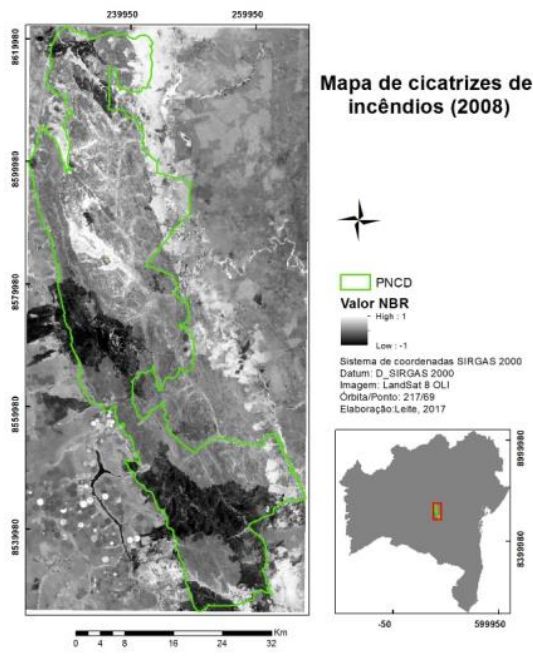

Figura 2: Mapa de cicatrizes de incêndios no PNCD referente ao ano 2008.

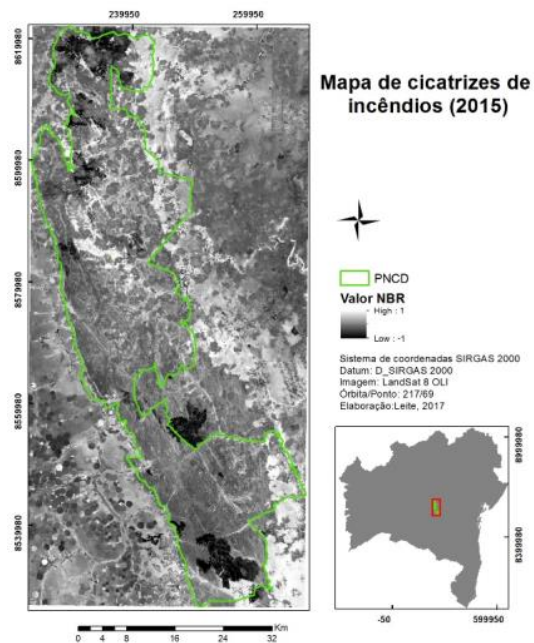

Figura 3: Mapa de cicatrizes de incêndios no PNCD referente ao ano 2015.

Nas figuras 2 e 3, observam-se extensas áreas com valores $N B R$ próximos a -1, ou seja, locais onde ocorreu queima da vegetação, sendo elas, no ano de 2008 correspondentes a 68,4 ha e no ano de 201522,5 ha. A banda do infravermelho próximo é muito utilizada em estudos da vegetação, visto que este material responde positivamente no intervalo espectral correspondente à banda supracitada e portanto, o índice $N B R$ a utiliza para identificar áreas recobertas por vegetação sadia (KEY e BENSON, 2006).

Por outro lado, a banda referente ao infravermelho de ondas curtas responde da mesma maneira à áreas onde a vegetação apresenta redução da clorofila. Sendo assim, o resultado do cálculo do índice mostra áreas bem marcadas com valores de índice abaixo de zero, quando há locais com vegetação queimada e áreas com valores de índice positivo, locais com vegetação sadia. Há ainda áreas classificadas com valores próximos a zero, as quais, segundo Key e Benson (2006), correspondem a presença de nuvens e/ou solo exposto.

A validação dos resultados foi realizada por inspeção de campo nos locais onde ocorreram queima no ano de 2015, visto que para o ano de 2008 não havia condições de fazêlo por conta do tempo decorrido desde então. A figura 4 observam-se locais marcados onde foi possível observar vegetação queimada, solo com aspecto queimado, entre outros vestígios deixados pelo fogo. 


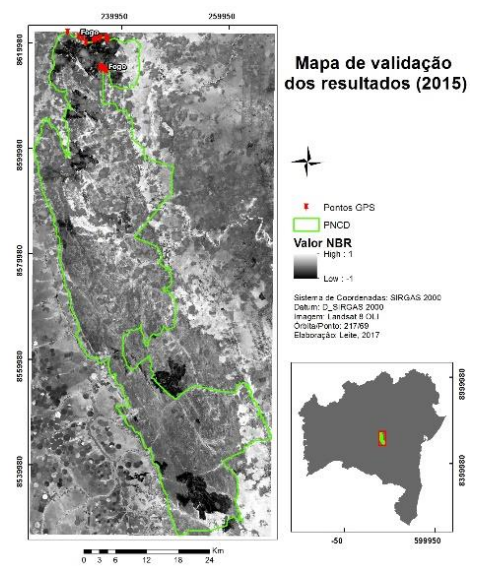

Figura 4: Mapa de validação dos resultados para o ano de 2015.

As validações foram restritas às manchas de queimada a norte do Parque por serem locais de mais fácil acesso e com maior extensão queimada nas proximidades do município de Lençóis. A outra grande área queimada em 2015 se encontra nos Gerais do Machobongo, no município de Mucugê, local de difícil acesso para inspeção de campo.

\section{CONSIDERAÇÕES FINAIS}

Ao final deste estudo, observa-se que a metodologia empregada foi bastante satisfatória e eficaz ao que se propôs.

O índice espectral NBR demonstrou bons resultados na discriminação das áreas queimadas e áreas não queimadas, de modo a possibilitar a constatação dos locais acometidos por incêndios nos anos de 2008 e 2015 no Parque Nacional da Chapada Diamantina e ainda quantifica-las.

Com a campanha de campo foi possível confirmar in loco os resultados alcançados pelo processamento digital da imagem, verificando que, após dois anos ainda há muitos vestígios deixados pelo incêndio.

\section{REFERÊNCIAS}

ALLEN, J. L.; SORBEL, B. 2008. Assessing the differenced Normalized Burn Ratio's ability to map burn severity in the boreal forest and tundra ecosystems of Alaska's national parks. International Journal of Wildland Fire.

ENVI, disponível em www.envi.com.br/index.php/modulos/acm. Acesso: 08 de Junho de 2017. HOFFMANN, W.A. Fire and population dynamics of woody plants in a neotropical savanna: matrix model projections. Ecology. 1999 v. 80, p. 1354-1369.

IBAMA. 2008. Parque Nacional da Chapada Diamantina - BA. Relatório de combate ampliado. IBAMA - PREVFOGO: Brasília. $11 \mathrm{fl}$.

KEY, C. H.; BENSON, N. C. 2006. Landscape assessment: Sampling and analysis methods USDA Forest Service General Technical Report RMRS-GTR-164-CD. Disponível em: <http://www.fs.fed.us/postfirevegcondition/documents/publications/FIREMON_LandscapeAs sessment.pdf $>$. Acesso em: 20 de maio de 2017.

LEITE, C. C. S. de S.; SILVA, A. de B.; SANTOS, S. M. B.; ROCHA, W. de J. S. da FRANCA. 2017. Utilização dos índices espectrais NBR e NDVI na caracterização de incêndios no PARNA Chapada Diamantina (Bahia): Estudo de caso dos Gerais do Machobongo. In: XVIII Simpósio Brasileiro de Sensoriamento Remoto, Santos: INPE. p. 2131-2137

JUNCÁ, F. A.; FUNCH, L. e ROCHA, W (org.). Biodiversidade e Conservação da Chapada Diamantina. Brasília: Ministério do Meio Ambiente. 2005 